Daiana dos Santos Reis e Aldair Oliveira de Andrade, no artigo Regime de Progressão Continuada e avaliação em uma escola estadual no município de Humaitá/AM, discutem o artigo $32 \S 2^{\circ}$ da LDB $n$ o 9.394/96, segundo o qual as instituições escolares podem utilizar o Regime de Progressão Continuada diretamente ligado à avaliação. A pesquisa demonstra estatística e descritivamente a realidade da avaliação neste Regime, destacando questões como tempo de aprendizagem, práticas avaliativas e acompanhamento individual a partir da perspectiva dos alunos do $9^{\circ}$ ano do Ensino Fundamental II, em uma Escola Estadual do Município de Humaitá/AM.

Na seção Educação, Ambiente e Saúde temos três artigos sobre esta temática em diferentes abordagens, de modo a ampliar as discussões.

Elias Francisco Amortegui Cedeno, Valentin Gavidia Catalan e Olga Mayoral García-Berlanga, no artigo Progresión de las ideas del profesorado en formación sobre las prácticas de campo en una secuencia de aprendizaje, tematizam o valor que as práticas de campo têm para o ensino e aprendizagem de Biologia, ao permitir que os estudantes abordem seu objeto de estudo, que é o ser vivo, o mais próximo possível de suas condições naturais. O estudo mostra a contribuição de um seminário formativo na progressão das concepções dos professores em formação sobre a natureza das Práticas de Campo, suas finalidades para a aprendizagem, seu planejamento e como auxilia a formação docente.

No artigo, As proposições do enfoque CTS nos livros didáticos de Ciências do 9o ano, Jucelino Cortez e Armando Foscarin Neto apresentam o resultado de uma pesquisa qualitativa em livros didáticos da disciplina de Física do 9o ano do Ensino Fundamental, do Plano Nacional do Livro Didático, utilizados na cidade de Passo Fundo, região norte do Rio Grande do Sul. Analisaram as formas e disposições com que os conteúdos são apresentados e trabalhados nestes livros, buscando identificar as vocações da abordagem CTS, para subsidiar gestores e professores da Educação Básica no momento da escolha desta ferramenta.

Wilka Karla Martins do Vale e Ruth do Nascimento Firme, no artigo $O$ experimento didático formativo e suas contribuições relativas ao processo de apropriação/objetivação da abordagem de questões sociocientíficas por professores de Ciências, observaram o desenvolvimento de um Experimento Didático Formativo (EDF) e identificaram as contribuições como método de investigação e de ensino, relativas ao processo de apropriação/objetivação da Abordagem de Questões Sociocientíficas (AQSC) por professores de ciências. O EDF foi composto por etapas e subetapas coerentes com alguns pressupostos teóricos e metodológicos da teoria histórico-cultural, a partir da teoria da atividade.

Convidamos os leitores a estudarem estes textos que trazem muitas discussões sobre educação, em sua diversidade de abordagens e temáticas.

Boa leitura

Doutora Maria Cristina Pansera-de-Araújo

Doutor Celso Martinazzo 


\title{
BASE NACIONAL COMUM CURRICULAR E (SEMI) FORMAÇÃO: Quais os Dilemas da Escola Atual?
}

\author{
Ademir Henrique Manfré ${ }^{1}$
}

\begin{abstract}
RESUMO
Este artigo trata do tema (semi)formação, Base Nacional Comum Curricular e escolarização. É resultado de reflexões e problematizações oriundas da disciplina de Currículo e Escola por mim ministrada nos cursos de Licenciatura de uma Universidade do Estado de São Paulo. Tem como objetivo geral refletir criticamente sobre as influências que a Base traz às políticas de formação docente na atualidade. Além do suporte bibliográfico educacional específico, o artigo amparou-se nas discussões teóricas desenvolvidas por Theodor Adorno em seus textos filosófico-educacionais discorrendo sobre o conceito de (semi) formação e educação. A análise proposta concluiu que a Base Nacional Comum poderá transformar a estrutura curricular brasileira não pelo caminho da formação cultural (Bildung), mas pelos interesses mercadológicos baseados em aspectos como competitividade, produtividade e empreendedorismo, reduzindo as possibilidades de crítica. Assim, a crítica adorniana à sociedade performática emerge como um referencial teórico que contempla a possibilidade de desenvolver em bases diferentes a análise do processo social em que se insere a educação escolar e seus vínculos com a semiformação.
\end{abstract}

Palavras-chave: BNCC. Escola. Teoria crítica. Formação.

COMMON NATIONAL CURRICULAR BASE AND (SEMI) TRAINING: WHAT IS THE DILEMAS FOR THE CURRENT SCHOOL?

\section{ABSTRACT}

In this article we deal with the topic of (semi) formation, the "Base Nacional Comum Curricular" (BNCC - National Curriculum Common Base), and schooling. It is the result of reflections and problematizations arising from the discipline "Curriculum and School" ("Currículo e Escola") taught by me at the Undergraduate courses at the State University of São Paulo. Our general objective is to develop a critical thought on the influences that the BNCC brings to the policies of teacher education nowadays. In addition to the specific educational bibliographic support, the article is based on the theoretical discussions developed by Theodor Adorno in his philosophical-educational texts discussing the concept of (semi) formation and education. The proposed analysis concludes that the BNCC can transform the Brazilian curricular structure not by the path of cultural formation (Bildung), but by market interests based on aspects such as competitiveness, productivity and entrepreneurship, reducing the possibilities of criticism. Thus, Adorno's critique about the performance society emerges as a theoretical reference that contemplates the possibility of developing the analysis of the social process on a different basis, in which school education is inserted and its links with the semiformation.

Keywords: BNCC. Scholl. Critical theory. Formation.

\footnotetext{
1 Doutorado em Educação pela Universidade Estadual Paulista Júlio de Mesquita Filho (2014). Educador Social do Centro de Referência de Assistência Social - Cras. Professor da Faculdade de Artes, Ciências, Letras e Educação - Faclepp/Unoeste. http://lattes.cnpq. br/2559786704613672. https://orcid.org/0000-0002-2067-4657. ademirmanfre@yahoo.com.br
} 


\section{CENÁRIOS DO DEBATE SOBRE BASE NACIONAL COMUM CURRICULAR E EDUCAÇÃO ESCOLAR}

Este ensaio trata do tema Base Nacional Comum Curricular (BNCC) e Educação Escolar. É fruto de inquietações realizadas junto a disciplina de Currículo e Escola por mim ministrada em um curso de Graduação de formação de professores.

As inúmeras publicações sobre a Base Nacional Comum, principalmente aquelas produzidas pelo Ministério da Educação (MEC) e pelo Movimento pela Base Nacional Comum $^{2}$ levou-nos a refletir criticamente sobre a natureza conceitual do referido documento.

Entre as temáticas tratadas pela Base destacamos aquelas que permeiam a formação docente reconhecidas como essenciais na promoção da qualidade da educação brasileira.

A análise das diferentes posições torna-se fundamental para refletirmos sobre o nível de centralização ocupado pela reforma curricular proposta. Trata-se, portanto, de apresentar reflexões sobre a Base Nacional e suas consequências para a educação escolar.

Nos últimos anos, a educação brasileira tem sido alvo de várias reformas justificadas como essenciais na geração de políticas públicas eficientes para o desenvolvimento de competências e habilidades tão requeridas pela sociedade do conhecimento. Pautadas em políticas neoliberais, essas reformas direcionam as propostas formativas dos indivíduos, provocando disputas em torno dessas proposições.

Albino e Silva (2019) argumentam que o conceito de competência não é algo novo no debate educacional. Nos EUA, na década de 60, o behaviorismo exerceu forte influência nos currículos educacionais, estabelecendo quais habilidades seriam mais adequadas no processo de ensino e de aprendizagem. Na Europa, a Organização das Nações Unidas para a Educação, Ciência e Cultura (Unesco) e a Organização do Comércio e Desenvolvimento Econômico (OCDE) são algumas das instituições responsáveis por imprimir um ensino mediado por competências e habilidades, logicamente pautado por modelos empresariais.

No Brasil, mais particularmente na década de 90, a proposta de formação escolar por competências foi apresentada em alguns documentos normativos, tais como as Diretrizes Curriculares Nacionais Gerais da Educação Básica, publicadas em 1999, os Parâmetros Curriculares Nacionais (PCNs) e os Parâmetros Curriculares Nacionais do Ensino Médio (PCNEM).

Nessa perspectiva, a formação humana é subalternizada a partir de uma série de condicionantes, sobretudo de ordem internacional. O currículo pautado nos fundamentos pedagógicos das competências é configurado como necessário não por uma necessidade nacional de pensar a formação humana integral, mas como resposta a uma demanda mundial (ALBINO; SILVA, 2019, p. 142).

Os principais são: http://portal.mec.gov.br/, http://movimentopelabase.org.br, http://undime-sc.org.br/ e http:// basenacionalcomum.mec.gov.br. 
No contexto da presente discussão, notamos que a emergência das competências no campo educacional passou a ser o elemento fundamental na resolução dos problemas educacionais. Desse ponto de vista, impõem-se aos professores e alunos novas aquisições (acadêmicas, técnicas, emocionais e sociais) diante dos diferentes contextos, complexos e imprevisíveis. Competências e habilidades são solicitadas aos indivíduos para fazerem frente aos desafios da sociedade do conhecimento. Ao indivíduo é sugerido sutilmente que seja produtor e portador de competências capazes de constituir um conjunto de valores (colaborativo, desempenho máximo, plasticidade e adaptabilidade) para sobreviver na sociedade em constante transformação.

Não é por acaso que, desde pequenas, nossas crianças são incentivadas a serem empreendedoras, planejadoras, dinâmicas, elementos esses vendidos como potencializadores do sucesso profissional.

Produtividade, racionalidade, lucratividade, capacidade de aprender a aprender constantemente - muitas vezes desvinculada do aprender a pensar - são apresentadas como pacotes de aptidões que os indivíduos necessitam desenvolver na escola contemporânea.

Entre o conjunto de reformas educacionais atuais, a Base Nacional Comum Curricular (BNCC) apresentou mudanças nas grades curriculares das escolas brasileiras, inserindo competências ${ }^{3}$ e habilidades específicas como elementos centrais na formação dos indivíduos.

Este texto trata basicamente da Base Nacional Comum Curricular do Ensino Fundamental, mais especificamente sobre a proposta de formação escolar presente no documento.

Partindo das considerações anteriores, lançamos os seguintes questionamentos: Qual é a importância de uma Base Nacional Comum Curricular para a educação? Por que instituir um Currículo Nacional? A quem interessa uma Base Nacional Comum?

O objetivo de tais questionamentos é apontar caminhos interpretativos críticos sobre o processo de elaboração da Base Nacional evidenciando um distanciamento das considerações otimistas de seus idealizadores.

\section{INICIANDO O DEBATE SOBRE A BASE}

O debate sobre uma Base Nacional Comum não é algo novo na história da educação brasileira. A Constituição Federal de 1988 , em seu artigo $210^{4}$ já propunha a elaboração de conteúdos mínimos para a formação do estudante. Esse dispositivo também foi apresentado pela Lei de Diretrizes e Bases da Educação Nacional (Lei $n^{\circ}$ 9394/96) em seu artigo 26, ${ }^{5}$ propondo a elaboração de uma Base Nacional Comum a ser complemen-

\footnotetext{
Sacristán (2011) enfatizou que a noção de competências visa a uma sociedade de indivíduos eficientes na maquinaria do sistema capitalista excludente. Além disso, em termos educacionais, as competências na educação são entendidas pelo autor como adestramento.

4 Art. 210. Serão fixados conteúdos mínimos para o Ensino Fundamental, de maneira a assegurar formação básica comum e respeito aos valores culturais e artísticos, nacionais e regionais.

Art. 26. Os currículos do Ensino Fundamental e Médio devem ter uma base nacional comum, a ser complementada em cada sistema de ensino e estabelecimento escolar, por uma parte diversificada, exigida pelas características regionais e locais da sociedade, da cultura, da economia e da clientela.
} 
tada em cada sistema de ensino. No atual Plano Nacional de Educação (2014-2024), a proposta de uma base nacional curricular apareceu como uma política curricular direcionada à formação humana integral, com amparo na qualidade social.

Entidades como o Movimento "Todos Pela Educação", "Movimento pela Base", "Instituto Ayrton Senna", entre outros, desempenharam um papel fundamental no alinhamento das políticas educacionais brasileiras às exigências neoliberais.

Pelo menos desde 2001 vem sendo articulado um movimento global denominado Germ - Global Education Reform Moviment (Movimento Global de Reforma da Educação), que visa a fortalecer as reformas educacionais por meio do que chama de eficácia dos sistemas educacionais. Está articulado em torno de três princípios da política educacional: padrões, prestação de contas e descentralização (HYPOLITO, 2019, p. 189).

Diante do exposto, em 2015 o Ministério da Educação iniciou a elaboração de um documento que definiria o que seria ensinado nas escolas. Especialistas foram convidados a compilar o texto, o qual teve pouca participação dos professores e estudantes das escolas. Assim, em 20 de dezembro de 2017 o MEC homologou a Base Nacional Comum Curricular.

Foi nessa conjuntura nacional e internacional que a reforma curricular ocorreu, pleiteando interesses alinhavados ao mercado educacional empresarial.

Instituída com a justificativa de organizar e dar mais coerência ao sistema educacional brasileiro, a Base Nacional Comum surgiu com a prerrogativa de alinhar os currículos das escolas, a formação dos professores, as avaliações e também os materiais didáticos às diretrizes educacionais internacionais.

Conceitualmente, a proposta é um documento normativo. Caracteriza-se como um conjunto de orientações, uma lista de conteúdos específicos que as escolas utilizarão como base para compor os seus currículos.

A Base Nacional Comum Curricular define os conhecimentos e habilidades essenciais que todos os estudantes brasileiros têm o direito de aprender, ano a ano, durante sua trajetória na Educação Básica. Adotar uma base curricular comum é fundamental para reduzir as desigualdades educacionais de uma nação. Ao definir o que é essencial ao ensino de todos os alunos em cada uma das etapas da vida escolar, as expectativas de aprendizado e critérios de qualidade ganham transparência e podem ser aplicadas e cobradas com maior eficiência (MOVIMENTO..., 2016, s/p).

Em outras palavras, significa dizer que a Base define os objetivos de aprendizagem eleitos como essenciais para a formação do indivíduo. Por meio de competências e habilidades específicas, os currículos devem ser constituídos traçando estratégias pedagógicas respeitando as particularidades sociais e regionais de cada instituição escolar. Diante do exposto, a perspectiva de uma educação integral é enfatizada. Nessa proposta, afirmam os proponentes da Base, os sistemas de ensino devem estar concatenados em quatro pilares, conforme exposto por Delors (1996): aprender a conhecer, aprender a fazer, aprender a ser e aprender a conviver, com ênfase no aprender a fazer. 
Na BNCC, competência é definida como a mobilização de conhecimentos (conceitos e procedimentos), habilidades (práticas, cognitivas e socioemocionais), atitudes e valores para resolver demandas complexas da vida cotidiana, do pleno exercício da cidadania e do mundo do trabalho (BRASIL, 2017, p. 8).

Diante do exposto, a contemporaneidade exige dos indivíduos performances sucessivas, elegendo valores como competitividade, espírito empreendedor: que vença o melhor, o mais esforçado, o mais bem preparado. Esse é o ponto nodal do estilo de existência estimulado pela competitividade global.

Notamos que os adeptos da Base Nacional Comum disseminam um discurso sedutor possível de resolver todos os problemas educacionais: veja, se a escola vai mal, é necessário começar uma reforma por seu currículo. Os currículos ultrapassados, metodologias tradicionais, direitos de aprendizagem insuficientes, estudantes com pouco capital cultural, formação de professores desconectada da performance global - elementos esses identificados como problemas escolares pelos adeptos da Base que não dão conta de formar o estudante do século 21 - seriam resolvidos pela instituição de um currículo padronizado para todos.

Levando em consideração que a Base Nacional Comum Curricular propõe-se a estruturar a Educação Básica, ${ }^{6}$ a análise do documento por nós tecida produziu um distanciamento em relação à proposta de formação escolar presente em seu texto. $O$ intuito aqui é problematizar as formas como a educação escolar é planejada de acordo com as exigências empresariais e suas regras de competitividade.

Posto isso, apresentaremos um recorte do texto normativo analisando a combinação entre competências e habilidades que, em nosso entendimento, está relacionada ao que Adorno (1996) conceituaram de semiformação.

A BNCC indica que as decisões pedagógicas devem estar orientadas para o desenvolvimento de competências. Por meio da indicação clara do que os alunos devem "saber" e, sobretudo, do que devem "saber fazer", a explicitação das competências oferece referências para o fortalecimento de ações que assegurem as aprendizagens essenciais definidas na BNCC (BRASIL, 2017, p. 13).

Foi nesse contexto que assistimos, a partir de 2013, o surgimento de um movimento que fomentou a proposta de criação de um currículo nacional com o objetivo de estabelecer uma Base Nacional Comum Curricular.

Foram três versões apresentadas até a homologação do documento final, em dezembro de 2017. É importante lembrar que as diferentes versões do texto articularam os interesses dos diferentes grupos empresariais, ${ }^{7}$ entre eles multinacionais, além de Organizações Não Governamentais. ${ }^{8}$

\footnotetext{
Na ocasião da elaboração deste artigo, a Base Nacional do Ensino Médio foi aprovada pelo Conselho Nacional de Educação, em 4 de dezembro de 2018. E mais, sem a participação popular.

Samsung Playstation, Avon, Natura, Nestlé, Telefônica, Shell, Grupo Globo, Odebrecht, Itaú, Citibank, Souza Cruz, Dudalina, Englishtown, entre outros grupos que se interessam pela privatização da educação.

8 Entre os grupos não governamentais, citamos: Fundação Itaú Social, Instituto Ayrton Senna, Fundação Lemann, Fundação Roberto Marinho, Fundação Cesgranrio, Instituto Unibanco. 
Dessa forma, os defensores da BNCC entendem que uma das mazelas da educação brasileira a ser superada é a ausência de um conteúdo básico e comum em todo o país. Já com uma BNCC teríamos a possibilidade de superar as desigualdades e a qualidade deficiente da educação (CURY et al., 2018, p. 61).

Essas considerações geraram a seguinte indagação: Qual o interesse do empresariado na educação brasileira?

Com o discurso de promover a melhoria da Educação Básica - chegando mesmo a um discurso humanitário - tendo como princípios competências e habilidades, a formalização de uma Base Nacional Comum Curricular para a educação garantiria "os direitos de aprendizagem de cada aluno, a formação de professores, os recursos didáticos e as avaliações externas" (MOVIMENTO..., 2015, p. 2).

A partir das considerações expostas, notamos que a relação entre educação de qualidade ${ }^{9}$ e desenvolvimento social são as molas propulsoras para o desenvolvimento do capital global.

Até aqui já apontamos que a educação brasileira é submetida a políticas que compartilham do receituário neoliberal. Nesse sentido, perguntamos: Quais impactos a Base Nacional Curricular traz à Educação Básica?

A Base traz várias modificações à prática pedagógica. A seguir elencamos algumas.

No que se refere à alfabetização ${ }^{10}$ escolar - um dos principais eixos da Base Nacional - a proposta é a de que os estudantes dos anos iniciais do Ensino Fundamental sejam alfabetizados até o fim do 2 o ano [proposta oposta apresentada pelo Plano Nacional de Educação (2014-2024), que sugere a alfabetização até o fim do 3o ano].

O documento normativo propõe uma interseção entre perspectiva construtivista e consciência fonológica. A ampliação do letramento infantil é a nova aposta do currículo escolar eleito pela Base.

\footnotetext{
Há no relatório Delors (1996, p. 163) a proposta de uma educação embasada nos indicadores de qualidade e equidade relacionados a competências. Por assim dizer: "os responsáveis pela educação deveriam abordar o problema da qualidade do ensino escolar em relação à melhoria das competências dos professores, concepção e elaboração de programas e aspectos conexos e gestão das escolas".

${ }^{10}$ O MEC tornou público na data de 15 de agosto de 2019 um manual de orientações sobre a nova política nacional de alfabetização. O evento foi marcado pela ausência das lideranças da Undime, órgão que representa as Secretarias Municipais de Educação. Na ocasião, o ministro da Educação, Abraham Weintraub, justificou que a Política Nacional de Alfabetização representa "um ponto de inflexão na educação brasileira" por incentivar uma metodologia científica do tema. A política de alfabetização do governo atual mantém o foco no chamado método fônico. Especialistas do campo escolar defendem que o MEC não deveria impor uma única pedagogia no processo de alfabetização escolar. Segundo os críticos, há discussões sobre a necessidade de conciliar diferentes metodologias de ensino e respeitar a autonomia das redes de ensino. A versão final do referido manual, entretanto, manteve a proposta pautada na abordagem fônica. De modo geral, o método fônico concentra atenção na relação entre letras e sons para, em seguida, chegar à leitura. Há a proposta de desenvolver materiais didático-pedagógicos para a recuperação de alunos com defasagem no processo de alfabetização. Na proposta do Ministério da Educação, entretanto, não há detalhes sobre como o projeto sairá do papel. O ministro da Educação sugeriu a criação de um grupo de 12 especialistas (os quais não tiveram os nomes divulgados) para elaborar um relatório com o objetivo de formular as políticas públicas no quesito da alfabetização. A ideia é envolver a análise de práticas pedagógicas e materiais didáticos, além de recomendações para aperfeiçoar a formação inicial e continuada de professores.
} 
Amparada na justificativa de que o Ensino Infantil deve ter uma ligação direta com o Ensino Fundamental, evitando possíveis lacunas, a Base sugere que o aprendizado deve ser contínuo, ou seja, não fragmentado. Com essa nova regra proposta pela Base Nacional, a alfabetização passa a ser o eixo principal dos professores de Língua Portuguesa nos dois anos iniciais do Ensino Fundamental.

A principal crítica dos estudiosos recai no fato de que a antecipação da alfabetização pode acelerar um processo que deveria ser paulatino e espontâneo no desenvolvimento das crianças, gerando dificuldades aos docentes e discentes, principalmente.

Nesse processo, a Educação Infantil foi escolarizada (com a definição de objetivos em três faixas de idade e agora com a redução da idade limite para alfabetização), introduziram-se habilidades socioemocionais, além de outras iniciativas mais internas à constituição dos conhecimentos (FREITAS, 2017, s/p).

As transformações propostas pela Base no quesito alfabetização ainda constituem um assunto pouco estudado, uma vez que poderá ser mais aprofundado quando a Base Nacional estiver na prática das escolas brasileiras, apresentando novos elementos analíticos.

Outro elemento proposto nesse debate diz respeito às avaliações. Segundo os técnicos do Ministério da Educação, as provas realizadas atualmente pelas escolas brasileiras são focadas na verificação de habilidades, ou seja, nas aprendizagens fundamentais esperadas por pelos estudantes em sua respectiva série escolar. As avaliações de larga escala - propostas pela Base - destacariam as tão almejadas competências (conjunto de conhecimentos mais amplos que abrange as habilidades). A justificativa é a de que a escola deve focar menos em conteúdos e centrar mais em uma formação que leve em consideração o que é possível fazer com o conhecimento adquirido, ou seja, uma perspectiva utilitarista (mas pouco formativa, em nosso entendimento).

Para que esse objetivo seja alcançado, o documento normativo apresenta pistas de como isso deve ser trabalhado nas escolas. De acordo com os fundamentos da BNCC, cada habilidade sugere que o conteúdo deve apresentar uma finalidade pedagógica. Dito de outro modo, o conteúdo sobre um determinado tema a ser ministrado deve portar uma intencionalidade para além das provas. É sob essa perspectiva que as avaliações devem ser formuladas, acreditam os técnicos do Ministério da Educação.

Nesse sentido, espera-se que a BNCC ajude a superar a fragmentação das políticas educacionais, enseje o fortalecimento do regime de colaboração entre as três esferas de governo e seja balizadora da qualidade da educação. Assim, para além da garantia de acesso e permanência na escola, é necessário que sistemas, redes e escolas garantam um patamar comum de aprendizagens a todos os estudantes, tarefa para a qual a BNCC é instrumento fundamental (BRASIL, 2017, p. 2).

Desse ponto de vista, a política educacional direcionada pelos organismos internacionais desencadeou "a emergência do Estado avaliador" (AFONSO, 2009, p. 122). Como tábua de salvação, a avaliação ${ }^{11}$ em larga escala toma proporção meteórica como instrumento auxiliar do Estado regulador.

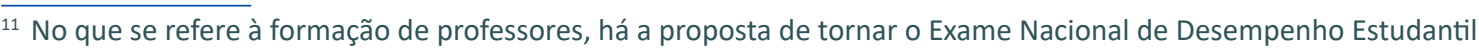
(Enade) anual para as licenciaturas alinhado à nova matriz de competências proposta pela Base. A ideia é tornar o referido exame obrigatório, servindo como habilitação à docência.
} 
De acordo com Cury et al. (2018), está no horizonte de que a Base Nacional Comum, por meio das avaliações padronizadas, se constituirá como estratégia de controle com o objetivo de verificar se os conteúdos de aprendizagem elencados pelo documento normativo foram alcançados. A pergunta é: Qual o sentido das avaliações propostas pela Base?

Diante disso, podemos estar diante de um efeito de homogeneização na educação brasileira com uma base nacional comum curricular que permitirá padronizar e alinhar metodologias, materiais didáticos, formação de professores, etc., o que poderá permitir a implantação da avaliação de desempenho do profissional da educação e transformar as escolas (pública e privada) em cursos preparatórios para melhorar o desempenho dos alunos e das instituições escolares nas avaliações externas, sejam elas quais forem: Prova Brasil, Saeb, Enem e o Pisa (DIAS; NOGUEIRA, 2017, p. 5).

Os livros didáticos seguirão as orientações da lista de conteúdos comuns para as diferentes séries do Ensino Básico. Diante do assinalado, Ribeiro e Rocha (2017, p. 1213) pontuaram que corremos o sério risco de privilegiar um projeto de poder que contempla determinados saberes e modos de vida. Dito de outro modo, "e diferentemente do que vêm enunciando distintas articulações discursivas, não se trata de uma base, mas de um teto para o qual devemos todos nos direcionar".

Em relação aos livros didáticos, portanto, não se trata apenas de uma simples seleção de conteúdos específicos que deverão ser trabalhados em um determinado ano escolar, mas sim de disputas na geração de significados daquilo que se entende por currículo. Em outras palavras, o que permeia esse debate é o discurso da "qualidade total em educação", com esta atingida sendo por meio da noção de direito à aprendizagem.

Ao definir quais conhecimentos e habilidades são fundamentais para se aprender em cada etapa da educação básica, a BNCC funciona como uma prática discursiva que envolve um jogo de prescrições que determina escolhas e, também, exclusões. Esse jogo de definição de "verdades", normalização, controle - consolidado a partir de uma tecnologia do corpo social - implica uma nova leitura da biopolítica, tomando como fio condutor a noção de "governo", isto é, tipos de racionalidade que envolvem conjuntos de procedimentos, mecanismos, táticas, saberes, técnicas e instrumentos destinados a dirigir a conduta dos homens: há, assim, o desdobramento das "artes de governar" (CARVALHO et al., 2017, p. 491).

Dito isso, os livros didáticos veicularão quais conhecimentos (aqueles selecionados pelos técnicos do Ministério da Educação e pelas instituições privadas) e habilidades são essenciais na formação do indivíduo contemporâneo.

Em relação à discussão sobre "Gênero e Orientação Sexual", o Conselho Nacional de Educação (CNE) retirou do documento da Base os elementos relacionados à temática em questão. A explicação para essa retirada foi que o tema é amplo e gerador de muitas controvérsias. Assim, debates devem ser aprofundados antes de qualquer publicação oficial, entendem os teóricos da Base Nacional e do Conselho Nacional de Educação (CNE).

As argumentações contrárias à inclusão da temática "Gênero e Orientação Sexual" nos currículos brasileiros justificam que tais conteúdos provocariam uma crise de identidade, podendo afetar a moralidade dos estudantes brasileiros. Também questionam o 
conceito de gênero, alegando que o fato de esse ser construído socialmente não se sustenta, necessitando de argumentos mais concretos. Outra linha de argumentação é a de que essa temática já foi contemplada no atual Plano Nacional de Educação (PNE). Desse modo, transparece a ideia de que nada mais precisa ser discutido quando o assunto é gênero!

Os defensores da inserção da temática nos currículos das escolas argumentam que a temática "Gênero e Orientação Sexual" é fundamental para a inclusão social, principalmente no combate às discriminações e na proposta de uma educação para a diversidade e ao respeito aos direitos humanos.

Se, por um lado, legitima-se a abordagem da sexualidade nos currículos, como fazê-la desatrelada das questões de gênero? Como abordar as múltiplas dimensões da sexualidade, as DST, o uso de contraceptivos sem destacar as desigualdades, os obstáculos e as hierarquias de gênero? Suprimir esses temas da BNCC reflete uma visão conservadora, mas, acima de tudo, desconsidera o acúmulo de debates, pesquisas e conquistas dos movimentos sociais em busca da equidade de direitos (SANTOS et al., 2018, p. 12).

Como o próprio documento afirma, a Base Nacional Comum está alinhada à Política Nacional de Formação docente. De acordo com Nóvoa (2002, p. 2), se nos anos 70 as reformas educacionais foram marcadas por intensa racionalização do ensino, os anos 80 por questões curriculares, os anos 90 pela administração e gestão dos estabelecimentos de ensino, hoje "parece ter voltado o tempo dos professores".

Nesse sentido, a Resolução $n^{\circ} 2$, de $1^{\circ}$ de julho de 2015, expressou esse alinhamento ao apontar para a capacitação do profissional da educação no sentido de colocar em prática "o projeto político pedagógico da instituição na perspectiva de garantir, com qualidade, os direitos e objetivos de aprendizagem e o seu desenvolvimento, a gestão democrática e a avaliação institucional" (BRASIL, 2015, p. 3-4). Assim, a formação docente deverá ser guiada por Programas (Residência Pedagógica, Pibid, ${ }^{12}$ por exemplo) que enfatizam a prática pedagógica, trazendo elementos do cotidiano para a sala de aula, aumentando a carga horária das práticas pedagógicas e diminuindo a carga horária teórica dos cursos presenciais.

[...] as diretrizes de formação propõem uma articulação à BNCC que não garante a qualidade da educação, já que os direitos e objetivos de aprendizagem e o seu desenvolvimento serão padronizados pela Base. [...] há 4 objetivos de formação que articulam a BNCC, a formação de professores e a avaliação em larga escala: "competência, qualificação profissional, empregabilidade e avaliação de desempenho". Uma triangulação que leva, consequentemente, e com base em experiências já vivenciadas em outros países, à padronização e eliminação da diferença ou do diferente em seus direitos à singularidade (SOUZA, 2018, p. 76).

\footnotetext{
12 Programa Institucional de Bolsas de Iniciação à Docência. Criado em 2007 pelo Ministérios da Educação (MEC), o referido programa oferece bolsas a alunos de Licenciaturas participantes de projetos de iniciação à docência desenvolvidos por Instituições de Educação Superior (IESs) em parceria com as redes de ensino. 
Pelo exposto, notamos que a proposta de uma Base Nacional Comum padronizada para a formação docente tem por objetivo ajustá-la à Base Nacional Comum Curricular da Educação Básica na perspectiva das competências, contribuindo para o aligeiramento da formação, seja em "cursos rápidos ou condensados e simplificados ministrados por faculdades de qualidade duvidosa, seja em cursos a distância ou em cursos baratos voltados para uma formação focada no mercado" (HYPOLITO, 2019, p. 197).

Constatamos que, no debate curricular atual há a associação entre formação e administração do saber pela definição e valorização da aquisição de competências e habilidades tão requeridas pelo mercado de trabalho, pela relativa flexibilização posta pelos projetos educativos.

Até aqui, apresentamos algumas discussões norteadoras do documento da Base. Vejamos agora outro eixo de reflexão sobre o tema, aquele que apresenta críticas $^{13}$ ao processo de elaboração e efetivação da Base Nacional Comum.

\section{BASE NACIONAL COMUM CURRICULAR E (SEMI)FORMAÇÃO: CRÍTICAS}

Nesta parte do texto concentramos nossa atenção no eixo de discussão crítica sobre Base Nacional Comum Curricular e educação escolar.

O intuito é problematizar o conceito de formação presente no documento da Base evidenciando o atrelamento de definições como competências e habilidades às propostas (semi)formativas. Para que se tenha uma ideia mais acertada sobre o que estamos aqui propondo, consideramos que a Base Nacional Comum Curricular parte de um conceito de formação oposto ao que estamos tratando neste debate. Em nossa leitura, formação na Base é sinônimo de qualificação, de certificação e de negação das resistências.

De antemão podemos afirmar que o documento - que em sua filosofia mostra-se inclusivo - pouco levou em consideração o "chão" da escola, ou seja, os atores sociais que nele estão. As competências definidas pelos especialistas do MEC sequer contaram com a participação efetiva dos protagonistas da escola: professores, alunos, diretores, pais, entre outros. Assim, "esse modo de segregação nos leva a crer que, de fato, os currículos nacionais ainda não conseguem dialogar com os pobres e sua pobreza" (ARROYO, 2015, p. 79).

Cury et al. (2018), Silva (2015), Dias e Nogueira (2017) e Ribeiro e Rocha (2017) afirmam que no texto normativo da Base está presente uma perspectiva técnica de políticas educacionais formativas. Assim, "o que ensinar" é entendido como desenvolvimento de competências e habilidades pautadas em conteúdos específicos regulamentados pelo Conselho Nacional de Educação.

Desse modo, constata-se a forma como as políticas educacionais estão sendo articuladas diretamente às regras do mercado de competitividade internacionais.

\footnotetext{
${ }^{13}$ Para Cury et al. (2018), o documento da BNCC não discute e muito menos aprofunda, por exemplo, a fundamentação sobre os processos avaliativos. Quais os critérios de avaliação? O que avaliar? Quem seleciona os saberes que serão avaliados? A partir da leitura do documento da Base, o que se nota são proposições teóricas genéricas com a valorização de conceitos como competências, empregabilidade e qualificação profissional. 
O que estamos colocando em questão é esse modelo das competências, de uma abordagem por competências que implica, de certo modo, em avaliar sistematicamente as "competências" adquiridas pelos alunos com critérios pré-estabelecidos. Trata-se de um método utilitarista que serve a determinadas teorias e projetos político-econômicos em que a razão neoliberal é determinante (DIAS; NOGUEIRA, 2017, p. 4).

Ramos (2001) argumenta que a Pedagogia das Competências aproxima-se muito mais de um saber instrucional do que de um saber proveniente da experiência e do pensamento reflexivo. Contrariamente a Perrenoud (2000) - conhecido como o pai da pedagogia das competências - a autora tece críticas aos valores do modo de produção capitalista transmitidos aos contextos formativos. Propõe uma pedagogia contra-hegemônica, criativa e transformadora construída com base no pensamento crítico, suprimindo o termo "competência".

Frigotto (2003, p. 4) observa que a pedagogia das competências sustenta a teoria de que o mercado é "o parâmetro de tudo. No campo educacional, esse conceito se expressa com os vocábulos como qualidade total, sociedade do conhecimento, educar por competências e para a competitividade, empregabilidade, produtividade".

Pelo exposto anteriormente, as noções de competências, habilidades e qualificação parecem ser os princípios últimos na formação do indivíduo na atualidade, atendendo às necessidades de mudanças educacionais em conformidade com o mercado de trabalho.

A cultura do empreendedorismo que assola nossa sociedade não é um mal em si mesmo, inclusive ela até poderia ser um modo de existência resistente dentro de outro registro histórico. A questão é que o modo pelo qual ela atua em nossa sociedade é endêmica, viral, age por contágio, quase que impossível de escapar. [o empreendedor] é investido desde tenra infância para, na fase produtiva, estar apto a atuar no mercado de trabalho. $O$ empreendedor deve investir constantemente em si mesmo, existe todo um aparato educacional para suprir, reciclar e conformar esse ethos empresarial (MORENO FILHO, 2015, p. 655).

Desse modo, ao se pensar um currículo por competências há o aprofundamento do individualismo, do aprender a aprender constantemente - muitas vezes desvinculado do aprender a refletir constantemente -- da meritocracia ${ }^{14}$ (que vença o melhor, o mais bem preparado, o mais esforçado), em que "o discurso das competências parece ser sedutor para trabalhar na evidência de sentido de uma educação supostamente democrática" (DIAS; NOGUEIRA, 2017, p. 5).

Diante da amplitude que caracteriza a temática, podemos indagar: Que impactos a Base Nacional Comum tem na prática?

No que se refere ao currículo, notamos um enfoque predominantemente tecnicista centrando sua proposta em "objetivos de aprendizagem". Dito de outro modo, essa perspectiva contém a ideia de que ao definir objetivos será possível verificar a aprendizagem. De que maneira? Por meio dos processos avaliativos, apresentados sem critérios claros.

${ }^{14}$ Não podemos deixar de ressaltar que o texto da BNCC segue ajustado às políticas operadas pelo Banco Mundial. 
A lógica bancária se enquadra em um trabalho com a BNCC em que o professor deve conhecer esta e transmiti-la aos alunos em uma relação que o mundo é de conhecimento do professor, transmitido pelos especialistas, e é, através dele - professor - que o aluno conhecerá o mundo (CURY et al., 2018, p. 121).

Tratando da formação docente, a Base Nacional Comum sugere uma reestruturação dos currículos dos cursos de formação de professores. Fato este evidenciado por intermédio de programas (e não de políticas) como o Programa Institucional de Bolsas de Iniciação à Docência (Pibid) e Residência Pedagógica formulados pela Coordenação de Aperfeiçoamento de Pessoal de Nível Superior (Capes/MEC).

São programas que instituem diversas mudanças nas Licenciaturas, uma vez que as Instituições de Ensino precisam se adequar a eles.

Muitos são os argumentos contrários à padronização, inclusive pondo em questão o sentido de uma BNCC: desqualificação dos docentes e do que é produzido nas escolas; aligeiramento nas ações e decisões políticas; polêmicas nas mudanças impostas em algumas áreas disciplinares; centralidade nos interesses mercadológicos; desconsideração das experiências que apontam para o fracasso da centralização curricular; desrespeito às diferenças/diversidade e às singularidades; desqualificação do imponderável da educação; o descrédito com as tradições curriculares e disciplinares; projeção de um ilusório discurso salvacionista para o currículo (RIBEIRO; ROCHA, 2017, p. 6).

É interessante destacar que, de acordo com os especialistas do Conselho Nacional de Educação, a Base Nacional Comum Curricular apresenta-se como uma solução eficaz aos problemas de ordem educacional na atualidade. Currículos ultrapassados, didáticas obsoletas, livros didáticos desconectados da prática pedagógica, formação docente em descompasso com a realidade atual são os principais argumentos dos defensores da instituição da Base utilizados para justificar a sua efetivação nas escolas brasileiras. Assim sendo, combate à fragmentação do saber, integração interdisciplinar curricular, objetivos de aprendizagem, mudanças na formação inicial de professores, referencial nacional para a formulação de currículos, referencial para propostas avaliativas são os principais elementos ressaltados pelo documento.

Com a justificativa de que a formação docente deve alcançar novos rumos, a Base Nacional é contemplada como uma diretriz salvacionista da educação escolar.

Diante do exposto, podemos afirmar a concepção de que a função principal da escola, que deveria ser a promoção da formação integral do estudante, cede lugar à formação para a geração de capital, de lucro para o mercado.

De acordo com Dourado e Oliveira (2018, p. 41) a Base atribui:

a) ênfase na regulação e controle do sistema educacional sobre o trabalho dos professores e das escolas, contribuindo, paradoxalmente, para secundarizar e/ou desqualificar o trabalho docente e para responsabilizar os professores pelo desempenho dos estudantes; b) entendimento restrito e conteudista da Base Nacional Curricular, visto como currículo único nacional com relação de conteúdos mínimos prescritivos (competências e habilidades); c) vinculação estreita entre currículo e avaliação em larga escala, configurando a centralidade nos resultados obtidos pelos estudantes nas provas nacionais de Português e Matemática, mais do que com os processos de formação. 
Parafraseando os autores supramencionados, o professor tornou-se uma espécie de Prometeu moderno na busca de resolução dos problemas educacionais. O professor, constrangido por políticas messiânicas, torna-se reprodutor de um modelo de educação que enfatiza o empreendedorismo, a produtividade e a competitividade.

Na BNCC, a tendência proposta para a formação humana é a modelizacão, a homogeneização por meio da acentuação dos processos de administração centralizada, ignorando as "realidades locais", suas especificidades, possibilidades e necessidades, buscando produzir identidades serializadas e eliminando as diferenças. Há uma fórmula estreita: um triângulo em cujos vértices estão a BNCC, a formação de professores e a avaliação em larga escala, estruturadas a partir de 4 objetivos de formação: competência, qualificação profissional, empregabilidade e avaliação de desempenho. Resultado: padronização e eliminação da diferença ou do diferente em seus direitos à singularidade (ANPED, 2016, p. 2).

Diante da amplitude que caracteriza a temática, torna-se necessária uma discussão crítica sobre Educação, Semiformação (Halbbildung) e políticas curriculares atuais.

No intuito de problematizar o modo como a Base Nacional Comum Curricular trata da temática formação destacamos o pensamento de Theodor Adorno e a sua crítica ao depauperamento da experiência (Erfahrung).

Tomamos o ensaio "Teoria da Semicultura" para evidenciar os limites de se pensar a formação humana prioritariamente pela performance do mercado - a qual enfatiza a instrumentalização do pensamento, conduzindo os indivíduos à adaptação a uma sociedade administrada, na qual "a centralidade da noção de competências no currículo, especialmente porque justificada e proposta pela via unidimensional do mercado, produz uma formação administrada ao reforçar a possibilidade de uma educação de caráter instrumental e sujeita ao controle" (SILVA, 2009, p. 449).

\section{COMO RESISTIR À INSTRUMENTALIZAÇÃO DO PENSAR?}

\section{O tema da Semiformação é central no pensamento adorniano.}

Os processos de tecnificação dos gestos e dos sentidos produzidos pelo ritmo frenético da produção industrial, pelo avanço da técnica e pela complexificação da vida resultaram em uma sensibilidade conformada aos ritmos cada vez mais velozes da sociedade performática.

O que nos chama a atenção em um dos principais textos de Adorno voltados ao tema da formação - Teoria da Semiformação (Halbbildung) - é a ênfase nos impasses do processo de formação, pois "a formação nada mais é que a cultura tomada pelo lado de sua apropriação subjetiva" (ADORNO, 1996, p. 389).

Essa ênfase revela um diagnóstico acerca da sociedade e uma aposta otimista no poder do pensamento crítico, cuja resistência em aceitar uma fórmula consoladora e conformista de formação acaba por indicar sua impossibilidade atual a fim de manter viva a possibilidade efetiva.

Para o frankfurtiano, a Semiformação não significa uma formação pela metade. Significa uma crise na formação; é algo a qual a formação se degenerou, ou seja, significa que a formação foi empobrecida e subordinada aos mecanismos da razão instrumental: cálculo, reificação e dominação. Essa limitação da "experiência formativa é alvo de 
muitas práticas vivenciadas por meio dos currículos escolares, e tendo sido responsável pela limitação da própria formação, por seu confinamento à condição de Semiformação" (SILVA, 2015, p. 369).

Adorno (1996, p. 405) enfatizou o conceito de experiência no processo de formação (Bildung).

A experiência - a continuidade da consciência em que perdura o ainda não existente - e em que o exercício e a associação fundamentam uma tradição no indivíduo - fica substituída por um estado informativo, pontual, desconectado, intercambiável e efêmero, e que se sabe que ficará borrado no próximo instante por outras informações.

O que compõe a experiência em Adorno?

Em Adorno (1996), a experiência se traduz numa abertura ao novo, ao indeterminado, suscita pensamentos, afetando o indivíduo de forma profunda. A Semiformação seria a negação da experiência, da formação (Bildung). ${ }^{15}$

Uma segunda característica da Semiformação - depois da negação da experiência - é a degeneração do próprio conceito com sua substituição pelo clichê ou pela falsa projeção, pelo preconceito. Numa passagem do livro "Dialética do Esclarecimento" encontramos a expressão "indivíduo semicultivado". Nela, detectamos tanto a degeneração da experiência quanto o que os autores chamam de "falsa projeção" - uma degeneração do conceito.

Se o conceito necessita de um ego bem formado, a Semiformação produzirá algo oposto ao conceito, constatou Pucci (1997).

$\mathrm{Na}$ sociedade pautada pela racionalidade instrumental e tecnológica, Adorno (1996) afirmou que a formação passa a ser mediada pelo princípio da troca, converte-se em mercadoria, em puro fetiche. A consequência imediata da Semiformação é a aniquilação do pensamento, pois "o inimigo que se combate é o inimigo que já está derrotado, o sujeito pensante" (ADORNO; HORKHEIMER, 1985, p. 140).

Podemos afirmar que o imperativo da Semiformação submete a formação cultural ao equivalente de troca para servir a seus fins.

Desse modo, essa formação meramente instrumental não é uma formação para a experiência, para pensar o próprio pensamento. É uma formação administrada, cuja finalidade é a preparação para o mercado de trabalho competitivo. A experiência do sujeito com o objeto é impedida de ocorrer, pois ao sujeito já não é mais possível pensar, resistir (ADORNO; HORKHEIMER, 1985).

O filósofo constatou que a atual consciência não está apta à experiência, pois apresenta-se como coisificada. Afirmou que a consciência coisificada é uma consciência amputada, pois é destituída de pensamento crítico e de reflexão.

\footnotetext{
${ }^{15}$ A Bildung representa, em Adorno (1996) o processo de estranhamento e reapropriação entre mundo e espírito, numa tensão contínua entre autonomia e adaptação, aceitação do mundo objetivo e negação, afirmação do espírito contrapondo à natureza. É um exercício em relação ao tempo, à memória, à história. Esse tensionamento constitui a cultura. A formação (Bildung) submetida às relações sociais regidas pela lógica mercantilista e instrumental acaba por converter-se no que Adorno chamou de Semiformação (Halbbildung).
} 
Assim, chega-se ao tema da educação.

Em Adorno (1996), a educação que se faz urgente é uma educação de resistência e para a contradição.

A partir do exposto, a educação teria por objetivo desmascarar as condições e condicionamentos do indivíduo e da sociedade. Nessa perspectiva, o indivíduo poderia ter ciência de seus próprios mecanismos, suas limitações, bem como de suas potencialidades. Para não andar na contramão da emancipação e da formação, caberia à educação reelaborar-se criticamente mediante um processo ininterrupto de autorreflexão consciente de que no atual contexto a educação filia-se às exigências do mundo da produção.

Notamos que ao mesmo tempo que Adorno (1996) apresentou um limite da identidade entre formação e educação, ele não negou o valor da Pedagogia. Pelo contrário, ela é indispensável. O frankfurtiano, entretanto, afirmou que a simples submissão do homem a preceitos disciplinares é uma violência contra a própria formação, pois poderiam [as reformas pedagógicas isoladas] até, em certas ocasiões, reforçar a crise, porque "abrandam as necessárias exigências a serem feitas aos que devem ser educados e porque revelam uma inocente despreocupação diante do poder que a realidade extrapedagógica exerce sobre eles" (ADORNO; HORKHEIMER, 1985, p. 388).

Adorno e Horkheimer (1985) ocuparam-se da crítica ao declínio da experiência com a exacerbação da técnica e da sociedade estruturada em uma forma reificada de compreensão da realidade.

Nosso olhar sobre a educação na contemporaneidade recai na tentativa de refletir sobre o processo de empobrecimento da cultura marcada por uma formação meramente técnica, descompromissada com o pensamento, com a autorreflexão, pois a padronização "é contrária ao exercício da liberdade e da autonomia, seja das escolas, seja dos educadores, seja dos estudantes em definirem juntos o projeto formativo que alicerça a proposta curricular da escola" (SILVA, 2015, p. 375).

No campo do debate sobre a Base Nacional Comum Curricular notamos o quanto essa proposta está vinculada ao aprender a aprender constantemente, processo esse desvinculado do aprender a pensar e a inconformar-se.

Essa parte do artigo foi uma tentativa de olhar para o texto de Adorno - Teoria da Semicultura - buscando refletir sobre o predomínio da razão instrumental escondida sob a aparente unilateralidade do progresso tecnológico.

Desse ponto de vista, a falta de experiência, de formação, significa um maior poder da racionalidade instrumental sobre a subjetividade.

Procuramos destacar que o declínio da formação na escola está ligado à impossibilidade de se estabelecer uma autorreflexão com o próprio pensamento.

O que assegura em Adorno o pensamento autorreflexivo é a autocrítica. Diante disso, pode-se afirmar que a função primeira do pensamento é oferecer resistência ao status quo. Para Adorno e Horkheimer (1996), a Ciência e a Pedagogia deveriam se deter em uma análise mais pormenorizada sobre os modos como a disciplina, a fetichização da técnica e a instrumentalização do pensar vinculam-se umas às outras na Semifor- 
mação do indivíduo. Ao recuperar o sentido autorreflexivo e crítico da escola, Adorno cobrou da educação o exercício permanente da autorreflexão crítica a ser recuperada em nome dos ideais de emancipação a serem preservados no tempo presente.

Daí o caráter imanente da formação, a formação sempre em formação, excluindo-se o perigo de soar como formação continuada (reciclagem, cursos de atualização, programas fragmentados e instrucionais) que, principalmente por ser instrumental, não se relaciona de forma alguma ao que se está descrevendo. Podemos afirmar com Adorno (1996) que o processo de formação é a negação constante da deformação, não como possibilidade ou ameaça, mas como realidade e objetividade. Não é por acaso que o movimento de autorreflexão é contínuo e se identifica com a formação da consciência. Em nossa concepção, uma pedagogia da resistência implica trabalhar a formação dos sujeitos nas contradições.

Pagni e Silva (2007, p. 256) afirmam que Adorno postulou que o professor que "estivesse disposto a pensar o próprio ofício deveria compreender as condições sociais e políticas que envolvem a atividade e se empenhar na reflexão sobre seus limites no mundo totalmente administrado".

\section{ALGUMAS CONSIDERAÇÕES}

Com a homologação da nova Base Nacional Comum Curricular para a escola básica brasileira, os professores depararam-se com uma listagem de conteúdos elaborados por especialistas a pedido do Ministério da Educação com os argumentos de que a educação necessita de uma nova orientação curricular, que as escolas mostram-se desconectadas da nova realidade mundial.

Privilegiando uma abordagem educacional por competências e critérios preestabelecidos, "o discurso das competências parece ser sedutor para trabalhar na evidência de sentido de uma educação supostamente democrática" (DIAS; NOGUEIRA, 2017, p. 5).

A partir dos recortes temáticos realizados percebemos que a proposta da Base Nacional Comum Curricular apresenta medidas no sentido de "modernizar" as grades curriculares das escolas públicas e privadas brasileiras, introduzindo o discurso da competitividade como promessa de flexibilizar a formação escolar.

De acordo com Rocha e Pereira (2019), a Base configurou-se como uma propositura burocrática e uniformizante, elegendo a cultura neoliberal em detrimento da cultura formativa, desqualificando a escola como um espaço produtor, autônomo, repleto de diversidades, limitando a prática educativa a um fazer instrumental, reduzindo o trabalho do docente ao treinamento e à classificação dos sistemas avaliativos regulatórios.

Manfredi (1996, p. 35) afirma que a pedagogia das competências possui um efeito destrutivel, uma vez que "destrói-se a diversidade, a cultura, é uma lógica disciplinadora e fabril. É o modelo de organização da fábrica traduzido para a organização escolar".

Segundo Chauí (2014, p. 133), sob a auréola da neutralidade e da objetividade dos conhecimentos técnico-científicos, as competências são um poderoso elemento ideológico para justificar (ocultando) o exercício da dominação. 
Levando em consideração que a Base tem como proposta fomentar as políticas curriculares educacionais, a nossa análise geral do documento produziu a necessidade de uma leitura crítica e distanciada a respeito do modo como o referido documento propõe a política de formação escolar. Nesse sentido, as palavras-chave preconizadas pelo documento são: competitividade, habilidade, empreendedorismo, capacitação, aprender a aprender, produtividade.

Nos recortes realizados procuramos argumentar que uma aprendizagem pautada por competências e habilidades depaupera as possibilidades de crítica e de resistência à racionalidade instrumental, pois

[...] a escola não pode ser aprisionada pela lógica do mercado e do apostilamento através de um projeto que busca homogeneizar a diferença, interromper o movimento dialético das relações humanas na construção do conhecimento desumanizando cada vez mais o processo educacional escolarizado (CURY et al., 2018, p. 99).

Nesse sentido, o pensamento adorniano refuta qualquer possibilidade que nega a crítica ao status quo. Em Teoria da Semicultura constatamos que uma educação que se limita a formar os indivíduos para a competitividade e para a produtividade - aspectos privilegiados pela indústria cultural e pelas necessidades mercadológicas - privilegia a instrumentalização do pensamento, "uma formação administrada, que aprisiona a consciência no limite do existente e dificulta a possibilidade de se ultrapassar a compreensão do mais imediato e superficial" (SILVA, 2015, p. 369).

Sob o prenúncio de uma pretensa democratização, o modelo de formação escolar proposto pela Base Nacional - aplicabilidade de conteúdos, proatividade, buscar soluções para problemas imediatos - parece ser o fim último da escola contemporânea.

Diante do exposto, entendemos que o currículo escolar está além de uma dimensão meramente prescritiva que indica conteúdos específicos, formas, métodos e objetivos de aprendizagem supostamente aplicáveis. Assim, é preciso reconhecer que o currículo "expressa também o fazer propriamente dito, as ações por meio das quais se realiza o processo formativo no tempo-espaço da escola, processo este nem sempre circunscrito ao que está prescrito" (SILVA, 2015, p. 370).

De acordo com Silva (2015), as propostas formativas preconizadas pela Base sugerem a formação de um indivíduo autoempreendedor, numa sutil tentativa de regular o que deve ser ensinado nas salas de aula brasileiras.

Diante disso, podemos estar diante de um efeito de homogeneização na educação brasileira, com uma base nacional comum curricular que permitirá padronizar e alinhar metodologias, materiais didáticos, formação de professores, etc., e isto é aliado a um reducionismo no desenvolvimento da aprendizagem simplificado/instrumentalizado no ensino de competências e habilidades (SILVA, 2018, p. 6).

A partir do exposto destacamos nesta última seção do texto que o declínio da formação nos moldes postulados por Adorno (1996) está intimamente ligado à impossibilidade de se estabelecer uma autorreflexão com a cultura, com o pensamento. Posto 
isso, insistimos na autorreflexão, a qual exige um tempo de elaboração do pensamento (e não uma formação aligeirada pautada em mecanismos regulados pelo empresariado educacional).

Assim, a autorreflexão em Adorno (1996) passa pela questão da formação cultural (Bildung) e não pela produção de competências e habilidades instrumentais. Na "Teoria da Semicultura" lê-se que "a única possibilidade de sobrevivência que resta à Bildung é a autorreflexão crítica sobre a Halbbildung em que necessariamente se converteu" (ADORNO; HORKHEIMER, 1996, p. 410).

Não por acaso Adorno (1996) afirmou que a formação deve ser cultivada. Por outro lado, a Semiformação (semi)forma indivíduos pobres em experiências comunicáveis, portanto conformados e em conformidade.

Formação é confronto, tensão. Semiformação é conformidade. Experiência, formação e autonomia perfazem-se em relações tensas.

A palavra formação, no senso comum, é utilizada para designar um período de instrução escolar ao cabo do qual, via de regra, uma pessoa se forma, ou seja, "ganha uma nova capacitação". Expressões comuns como "sou formada em matemática", "formei-me no ano passado", "qual é a sua formação profissional?" manifestam uma das visões, a de certificação, que podemos atribuir ao termo formação. Em nossa compreensão, formação situa-se no paradigma do não acabado. A formação - compreendida como aprendizagem permanente - afigura-se como um processo próprio dos seres vivos. Ocorre sempre, ainda que de diferentes formas, com diferentes intencionalidades e com diferentes qualidades (ARAÚJO; MOURA, 2008, p. 76-77).

Na escola, a Semiformação fica evidente no saber fragmentado, nas metodologias e didáticas empobrecedoras, no ensino instrumentalizado, no desprestígio do professor como fonte de saber, nas atividades voltadas para o "aprender a aprender", no tempo administrado com o objetivo de "formar" mais em menos tempo, no aligeiramento da formação mediada por modelos empreendedores externos à escola.

Diante da amplitude que caracteriza a temática, este artigo buscou desde o início sublinhar que a Semiformação presente nas propostas curriculares atuais está ligada ao pensamento instrumental, à ausência do pensamento autorreflexivo e crítico. Com isso, análises e reflexões do pensamento adorniano foram tomadas como possibilidades de tensão, de contradição, de resistência e de formação.

Nossa discussão passa pela crítica de análises superficiais presentes nas propostas formativas contemporâneas, em que resistência e inconformismo são maneiras possíveis de manifestação de uma individualidade que só pode ser pensada em sua negatividade, concebeu Adorno (1996). A resistência em Adorno é o resultado depurado da exigência de se manter a tensão perene entre pensamento e realidade.

Do mesmo modo que para a formação é essencial que se tenha tempo para experimentar, para tocar, para elaborar, para refletir, para experimentar, pensamos que a escola, na condição de lócus privilegiado para a educação, deveria favorecer um pensamento para a resistência e para a contradição. Para não andar na contramão da formação e da emancipação, caberia à educação reelaborar-se criticamente mediante um processo ininterrupto de autorreflexão consciente de que, no atual contexto, a educa- 
ção filia-se às exigências do mundo da produção. Entendemos o "chão" escolar como um espaço conflituoso, cheio de significações de seus diferentes atores sociais. É um espaço de permanente ação, reflexão e crítica permeada por valores que não devem ser controlados pelos legisladores neoliberais excludentes.

Cabe então repensar a noção de currículo nacional entendendo-o como uma rede de interlocução de diferentes saberes, de diferentes aprendizagens, de diferentes experiências e de diferentes atores, e não simplesmente como uma lista de conteúdos elaborados por especialistas a pedido do Ministério da Educação. Importa, portanto, conceber o currículo como uma rede de saberes que se interconectam numa multiplicidade de problematizações e experimentações pedagógicas.

\section{REFERÊNCIAS}

ADORNO, Theodor W. Teoria da Semicultura. Trad. Newton Ramos-de-Oliveira, Bruno Pucci e Cláudia B. M. Abreu. Educação e Sociedade, Campinas, São Paulo, n. 56, p. 388-441, dez. 1996.

ADORNO, Theodor W.; HORKHEIMER, Max. Dialética do esclarecimento: fragmentos filosóficos. Tradução Guido Antônio de Almeida. Rio de Janeiro: Zahar Ed., 1985.

AFONSO, Almerindo Janela. Avaliação educacional: regulação e emancipação. 4. ed. São Paulo: Cortez, 2009.

ALBINO, Ângela C. A.; SILVA, Andréia F. BNCC e BNC da formação de professores: repensando a formação por competências. Revista Retratos da Escola, Brasília, v. 13, n. 25, p. 137-153, jan./maio 2019.

ANPED. Exposição de motivos sobre a Base Nacional Comum Curricular. 2016. Disponível em: http://www. anped. org.br/sites/default/files/resources/Of_cio_01_2015_CNE_BNCC.pdf. Acesso em: 1ำago. 2019.

ARAUJO, Elaine S.; MOURA, M. Contribuições da teoria histórico-cultural à pesquisa qualitativa sobre formação docente. In: PIMENTA, Selma G.; FRANCO, M. Pesquisa em educação. São Paulo: Ed. Loyola, 2008. p. 71-84. V. 1.

ARROYO, Miguel. Pobreza e currículo: uma complexa articulação. Brasília: MEC, 2015.

BRASIL. LDBEN - Lei de Diretrizes e Bases da Educação Nacional. Lei no 9.394/96. Disponível em: http//: www.planalto.gov.br/ccivil_03/leis/19394.htm. Acesso em: 1ำ ago. 2019.

BRASIL. Base Nacional Comum Curricular. Versão final. Brasília: MEC; CONSED; UNDIME; MPB, 2017.

BRASIL. Resolução $n^{\circ} 2$, de $1^{\circ}$ de julho de 2015. Define as Diretrizes Curriculares Nacionais para a formação inicial em nível superior (cursos de licenciatura, cursos de formação pedagógica para graduados e cursos de segunda licenciatura) e para a formação continuada. Brasília: MEC; CNE. Disponível em: http:// portal.mec.gov.br/docman/agosto-2017-pdf/70431-res-cne-cp-002-03072015-pdf/file. Acesso em: 12 ago. 2019.

BRASIL. Constituição da República Federativa do Brasil (1988). Brasília: DF: Presidência da República. Disponível em: http://www.planalto.gov.br/ccivil_03/constituicao/constituição.htm. Acesso em: 1ㅇa. ago. 2019.

CARVALHO, Janete et al. A base nacional comum curricular e a produção biopolítica da educação como formação de "capital humano". Revista E-Curriculum, v. 15, n. 2, p. 481-503, abr./jun. 2017. Disponível em: http//:revistas.pucsp.br/index.php/curriculum. Acesso em: 31 jul. 2019.

CHAUÍ, Marilena. Contra o discurso competente. In: ROCHA, André (org.). Escritos de Marilena Chauí. São Paulo: Ed. Fundação Perseu Abramo, 2014. p. 113-115.

CURY, Carlos R. et al. Base Nacional Comum Curricular: dilemas e perspectivas. São Paulo: Cortez, 2018. DELORS, Jacques. Educação: um tesouro a descobrir. Relatório para a Unesco da Comissão Internacional sobre Educação para o século XXI. São Paulo: Cortez, 1996.

DIAS, Juciele; NOGUEIRA, Luciana. O político-ideológico na (nova) Base Nacional Comum Curricular: uma análise discursiva das competências e habilidades. In: SEAD, 8., O político na análise do discurso: contradição, silenciamento, resistência. 2017, Recife. Anais [...]. Recife, 12 a 15 set. 2017. p. 1-10. Disponível em: http://www.sead.com.br. Acesso em: 12 nov. 2018.

DIAS, Isabel. Competências em educação: conceito e significado pedagógico. Revista Semestral da Associação Brasileira de Psicologia Escolar e Educacional, São Paulo. v. 14, n. 1, p. 73-78, jan./jun. 2010. Disponível em: http://www.scielo.br/pdf/pee/v14n1/v14n1a08. Acesso em: 2 ago. 2019. 
DOURADO, Luiz F.; OLIVEIRA, João F. Base Nacional Comum Curricular (BNCC) e os impactos nas políticas de regulação e avaliação da educação superior. In: AGUIAR, Márcia; DOURADO, Luiz F. (org.). A BNCC na contramão do PNE 2014-2024: avaliação e perspectivas. [Livro Eletrônico]. Recife: Anpae, 2018. p. 38-44. FREITAS, Luiz C. Os reformadores empresariais da educação e a disputa pelo controle do processo pedagógico na escola. Educação e Sociedade, Campinas, São Paulo, v. 35, n. 129, p. 1.085-1.114, out./dez. 2017.

FRIGOTTO, Gaudêncio. Educação e crise do capitalismo real. 5. ed. São Paulo: Cortez, 2003.

HYPOLITO, Álvaro Moreira. BNCC, agenda global e formação docente. Revista Retratos da Escola, Brasília, v. 13, n. 25, p. 187-201, jan./maio 2019.

MACEDO, Elizabeth. Base Nacional Comum para currículos: direitos de aprendizagem e desenvolvimento para quem? Educação e Sociedade, Campinas, São Paulo, v. 36, n. 133, p. 891-908, out./dez. 2015.

MANFREDI, Silvia Maria. Formação sindical no Brasil: história de uma prática cultural. São Paulo: Escrituras Editora, 1996.

MORENO FILHO, José W. N. Cultura do empreendedorismo: modo de vida e microfascismo contemporâneo. SIEF: SIMPÓSIO INTERNACIONAL EM EDUCAÇÃO E FILOSOFIA, 6., 2015, Presidente Prudente. Anais [...]. Presidente Prudente, SP: Universidade Estadual Paulista; FCT, 2015. p. 651-66.

MOVIMENTO PELA BASE NACIONAL COMUM. A Base. 2016. Disponível em: http://basenacionalcomum. org.br/a-base. Acesso em: 2 nov. 2018.

MOVIMENTO PELA BASE NACIONAL COMUM. Necessidade e construção de uma Base nacional Comum. 2015. Disponível em: http://basenacionalcomum.org.br. Acesso em: 29 set. 2018.

NóVOA, Antônio. Formação de professores e trabalho pedagógico. Lisboa: Educa, 2002.

PAGNI, Pedro A.; SILVA, Divino J. A crítica da cultura e os desafios da Educação após Auschwitz: uma leitura a partir da Teoria Crítica da Escola de Frankfurt. In: PAGNI, Pedro A.; SILVA, Divino J. (org.). Introdução à filosofia da educação: temas contemporâneos e história. São Paulo: Avercamp, 2007. p. 243-271.

PERRENOUD, Phillipe. Dez novas competências e habilidades para ensinar. Porto Alegre: Artmed, 2000.

PUCCI, Bruno. A teoria da Semicultura e suas contribuições para a teoria crítica da educação. In: ZUIN, Antônio A. S.; PUCCI, Bruno; RAMOS-DE-OLIVEIRA, Newton (org.). A educação danificada: contribuições à teoria crítica da educação. Petrópolis, Rio de Janeiro: Vozes, 1997. p. 89-113.

RAMOS, Marise Nogueira. A pedagogia das competências: autonomia ou adaptação? São Paulo: Cortez, 2001.

RIBEIRO, Willian; ROCHA, Simony. Sentidos de currículo e de Base Nacional Comum Curricular: disputas discursivas em um curso de formação de professores. Revista de Educação, Ciências e Matemática. v. 7, n. 2, p. 4-23, maio/ago. 2017.

ROCHA, Nathália F.; PEREIRA, Maria Z. C. Base Nacional Comum Curricular: os discursos sobre a docência. Revista Retratos da Escola, Brasília, v. 13, n. 25, p. 203-217, jan./maio 2019.

SACRISTÁN, José G. (org.). Saberes e incertezas sobre o currículo. Porto Alegre: Penso, 2011.

SANTOS, Nathany et al. Documentos curriculares oficiais assegurando a abordagem de gênero e sexualidade para a educação básica: um olhar para o ensino de ciências. In: SIMPÓSIO GÊNERO E POLÍTICAS PÚBLICAS: GÊNERO, EDUCAÇÃO E ESCOLA, 5., Londrina, PR: Universidade Estadual de Londrina, 13 a 15 jun. 2018. Disponível em: http://uel.br/eventos/gpp/pages/arquivos/VSGPP-\%20GT9. Acesso em: 10 ago. 2019.

SILVA, Mônica R. Currículo, Ensino Médio e BNCC: um cenário em disputas. Revista Retratos da Escola, Brasília, DF, v. 9, n. 17, p. 367-379, jul./dez. 2015. Disponível em: http//: www.esforce.org.br. Acesso em: 2 dez. 2018.

SILVA, Mônica R. Tecnologia, trabalho e formação na reforma curricular do Ensino Médio. Cadernos de Pesquisa, São Paulo, v. 39, n. 137, p. 411-430, maio/ago. 2009.

SOUZA, Rachel F. T. de. Os efeitos da BNCC na formação docente. Revista Okara, v. 12, n. 1, p. 69-79, jul. 2018. Disponível em: http//: www.okara.ufpb.br. Acesso em: 10 jul. 2019. 